\title{
EFEITO DO AMBIENTE SOBRE A DENSIDADE DA MADEIRA EM DIFERENTES FITOFISIONOMIAS DO ESTADO DE MINAS GERAIS
}

\author{
Gabriel Marcos Vieira Oliveira1, José Márcio de Mello², Paulo Fernando Trugilho³, José Roberto Soares Scolforo4, \\ Thiza Falqueto Altoé1, Antônio José da Silva Neto', Antônio Donizette de Oliveira ${ }^{3}$
}

(recebido: 26 de setembro de 2010; aceito: 31 de janeiro de 2012)

\begin{abstract}
RESUMO: Existem importantes fatores ambientais que afetam diretamente a taxa de crescimento das espécies florestais, que podem provocar alterações em suas propriedades e, por sua vez, afetar a densidade da madeira. Como a ocorrência das diferentes fitofisionomias está relacionada a fatores ambientais característicos, neste trabalho, objetivou-se verificar o comportamento geral da densidade da madeira das espécies arbóreas nativas, frente a essas diferentes condições de crescimento no estado de Minas Gerais. Os dados de cubagem rigorosa das árvores foram obtidos do Inventário Florestal de Minas Gerais. Foram utilizados dados de 1988 árvores nas diversas fisionomias florestais. De cada árvore foram retirados cinco discos de madeira nas posições 0, 25, 50, 75 e 100\% da altura total. A densidade básica de cada disco foi determinada segundo a norma NBR 7190/1997. As fitofisionomias ombrófila, semidecídua, cerradão, cerrado típico e decídua apresentaram, respectivamente, médias de densidade da madeira de 0,502; 0,561; 0,$585 ; 0,612$ e $0,675 \mathrm{~g} . \mathrm{cm}^{-3}$, todas estatisticamente distintas. Foi encontrada uma relação clara e coerente da densidade da madeira com as características edafoclimáticas que condicionam as diferentes fitofisionomias no estado de Minas Gerais. As fisionomias florestais apresentam condições ambientais tão características, que afetam a composição florística e, também, a atividade fisiológica e cambial das plantas, ocasionando densidades da madeira próprias às formações florestais.
\end{abstract}

Palavras-chave: Densidade básica, fisionomia florestal, Inventário Florestal de Minas Gerais.

\section{ENVIRONMENT EFFECTS ON WOOD DENSITY OF VEGETATION TYPES IN MINAS GERAIS STATE - BRAZIL}

\begin{abstract}
The objective was to verify the general behavior of wood density of native tree species in forest types in Minas Gerais state. The trees scaling data were obtained from the Forest Inventory of Minas Gerais State. Were used data from 1988 trees distributed in different forest formations. From each tree, five discs of wood were removed, at the 0, 25, 50, 75 and 100\% of the total height. The wood basic density of each disk was determined according to NBR 7190/1997. The ombrophylous forest, semideciduous forest, savanna woodland, typical savanna and deciduous forest presented average wood density of 0.502, 0.561, $0.585,0.612$ and $0.675 \mathrm{~g} . \mathrm{cm}^{-3}$, respectively, all statistically different. It was found a clear and consistent relation between wood density and environment characteristics that affect the different vegetation types in Minas Gerais State. The forest formations present environmental conditions so typical that they affect the floristic composition and also the cambial and physiological activity of plants, causing particular wood densities to forests formations.
\end{abstract}

Key words: Basic density, forest physiognomy, Forest Inventory of Minas Gerais State.

\section{INTRODUÇÃO}

Fatores ambientais influenciam a variabilidade da madeira, uma vez que afetam a taxa de crescimento das espécies florestais (RIGATTO et al., 2004). O efeito no crescimento está relacionado ao impacto sobre o período vegetativo e aos processos fisiológicos das plantas (ANTONOVA; STASOVA, 1997). Como resposta, as árvores adaptam seus processos fisiológicos de acordo com as condições ambientais, com reflexo na atividade cambial e na anatomia do lenho (VILLAR et al., 1997). Como a densidade da madeira é resultado da combinação da quantidade e da distribuição dos diferentes elementos anatômicos (ROQUE; TOMAZELLO FILHO, 2009), as variações edafoclimáticas, certamente, irão afetá-la de alguma maneira.

\footnotetext{
${ }^{1}$ Engenheiro Florestal, Doutorando em Engenharia Florestal - Departamento de Ciências Florestais - Universidade Federal de Lavras - Cx. P. 3037 37200-000 - Lavras, MG, Brasil - gabrielmvo@gmail.com, thizaaltoe@gmail.com, antoniojsnd@yahoo.com.br

${ }^{2}$ Engenheiro Florestal, Professor Doutor em Recursos Florestais - Departamento de Ciências Florestais - Universidade Federal de Lavras - Cx. P. 3037 37200-000 - Lavras, MG - josemarcio@dcf.ufla.br

${ }^{3}$ Engenheiro Florestal, Professor Doutor em Ciências Florestais - Departamento de Ciências Florestais - Universidade Federal de Lavras/UFLA Cx. P. 3037 -37200-000 - Lavras, MG - trugilho@dcf.ufla.br, donizete@dcf.ufla.br

${ }^{4}$ Engenheiro Florestal, Professor Doutor em Engenharia Florestal - Departamento de Ciências Florestais - Universidade Federal de Lavras - Cx. P. 3037 37200-000 - Lavras, MG - scolforo@dcf.ufla.br
}

Cerne, Lavras, v. 18, n. 2, p. 345-352, abr./jun. 2012 
Condições ambientais desfavoráveis ao crescimento das espécies florestais, normalmente caracterizadas por deficiência hídrica, baixas temperaturas e solos de baixa fertilidade estão, em geral, correlacionadas com altas densidades da madeira, em que a atividade fisiológica e cambial das plantas é reduzida. Por outro lado, baixas densidades da madeira estão associadas a ambientes favoráveis ao crescimento com disponibilidade e boa distribuição hídrica, temperaturas mais elevadas e solos mais férteis e de boa qualidade (BAKER et al., 2004; MULLERLANDAU, 2004; ROQUE; TOMAZELLO FILHO, 2009). Ambientes favoráveis ao crescimento, nos quais a atividade fisiológica e cambial das plantas é plena, resultam em divisão celular mais intensa, geralmente não acompanhada de um espessamento proporcional da parede celular, o que segundo Bergès et al. (2008), proporciona densidade da madeira mais baixa em função de uma proporção inferior de lenho tardio em relação ao lenho inicial. Além de que, segundo Trovati e Ferraz (1984), o próprio lenho tardio pode ser mais estreito e de baixa densidade nessas condições. Apesar dessa relação não ser absoluta para todas as espécies, é a mais coerente e mais encontrada na literatura.

Como a ocorrência das diferentes fitofisionomias está relacionada a fatores edáficos, topográficos e climáticos (AGNES et al., 2007; OLIVEIRA-FILHO et al., 1990; RODRIGUES et al., 2003; VELOSO et al., 1991), a hipótese a ser verificada é que os mesmos fatores ambientais que condicionam as fitofisionomias também resultem em efeitos significativos sobre a densidade da madeira das espécies presentes nas mesmas. A maioria dos estudos sobre efeitos do ambiente na densidade da madeira são pouco conclusivos e restritos a uma única espécie e, eventualmente, a pequenos grupos de espécies. Assim, neste trabalho, objetivou-se verificar o comportamento geral da densidade da madeira das espécies arbóreas nativas, frente às diferentes condições ambientais de crescimento nas fitofisionomias no estado de Minas Gerais.

\section{MATERIAL E MÉTODOS}

\subsection{Origem dos dados}

Os dados de cubagem rigorosa das árvores foram obtidos do Inventário da Flora Nativa e dos Reflorestamentos do Estado de Minas Gerais, um projeto realizado pelo governo do estado de Minas Gerais em parceria com o Instituto Estadual de Florestas - IEF e a Universidade Federal de Lavras - UFLA (SCOLFORO et al., 2008).

Cerne, Lavras, v. 18, n. 2, p. 345-352, abr./jun. 2012
Foram utilizados dados de 1988 árvores cubadas, totalizando 340 espécies, com diâmetro maior que $5,0 \mathrm{~cm}$, distribuídas em classes de diâmetros e altura, em diferentes bacias e sub-bacias hidrográficas e nas fisionomias florestais: ombrófila, semidecídua, cerrado típico, cerradão e decídua. As árvores cubadas foram retiradas de áreas em que o processo de desmate já havia sido autorizado pelo IEF para fins agropecuários ou planos de manejo sustentado (RUFINI et al., 2010). Na Figura 1, foram representados os locais do estado de Minas Gerais onde as árvores foram cubadas rigorosamente.

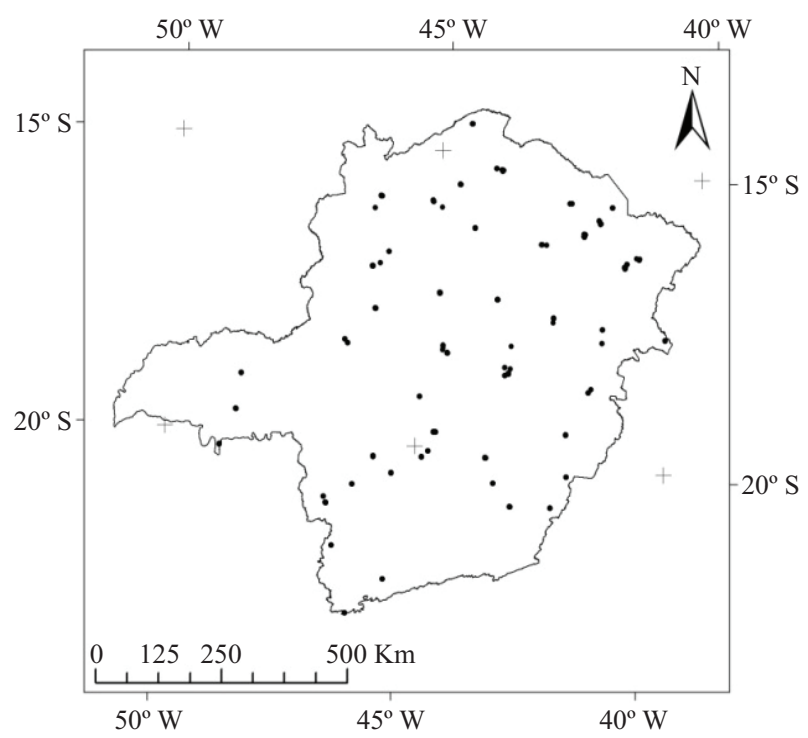

Figura 1 - Locais do estado de Minas Gerais onde foram realizadas as cubagens rigorosas das árvores.

Figure 1 -Locations of Minas Gerais state where the trees rigorous scaling were accomplished.

\subsection{Cubagem rigorosa}

O procedimento de cubagem foi executado, medindo-se o diâmetro mediano das seções compreendidas entre 0,$10 ; 0,30 ; 0,70 ; 1,00 ; 1,30$ e $2,00 \mathrm{~m}$ e, em seguida, de metro em metro, até o fim do fuste. Em relação aos galhos, foram cubados aqueles maiores que $3,0 \mathrm{~cm}$ de diâmetro e os comprimentos das seções foram arbitrários. Os volumes das seções do fuste e dos galhos foram determinados segundo o método de Huber, sendo o volume parcial e total da árvore a partir da soma das respectivas seções.

Após a cubagem, foram retirados cinco discos de madeira com espessura de $3,0 \mathrm{~cm}$ com casca, nas alturas 
correspondentes a $0,25,50,75$ e $100 \%$ da altura total da árvore. Os discos foram devidamente identificados com plaquetas de alumínio, de acordo com a árvore, posição do disco no fuste e local de coleta.

\subsection{Determinação da densidade básica da madeira}

Os discos seguiram para o Laboratório de Ciência e Tecnologia da Madeira (DCF/UFLA), onde foi realizada a determinação da densidade básica dos mesmos.

Inicialmente, foram retiradas duas cunhas opostas em relação à medula de cada disco de madeira. Posteriormente, a densidade básica de cada disco da árvore foi obtida a partir da média aritmética entre as duas cunhas. A densidade básica de cada cunha foi determinada segundo o procedimento descrito pela norma NBR 7190 (ASSOCIAÇÃO BRASILEIRA DE NORMAS TÉCNICAS - ABNT, 1997).

A densidade básica de cada árvore foi calculada pela ponderação das densidades básicas de cada disco pelo volume das seções correspondentes.

\subsection{Análise dos dados}

Uma análise de variância da densidade básica da madeira foi executada considerando como fator de variação as fitofisionomias envolvidas. O teste de Scott Knott foi adotado para comparação múltipla de médias, caso a análise de variância detectasse diferenças significativas. Para a execução das análises foi utilizado o software SISVAR (FERREIRA, 2008).

A suficiência das amostras utilizadas foi verificada com base em um nível de $95 \%$ de confiança, com erro máximo admissível de $5 \%$ com base no cálculo na intensidade amostral requerida (SHIVER; BORDERS, 1996). Os cálculos foram executados por meio do software R (R DEVELOPMENT CORE TEAM, 2008).

Para estimativa do parâmetro da densidade básica da madeira, em cada fitofisionomia, foi utilizado o método estatístico de estimação por intervalo de confiança para a média populacional (FERREIRA, 2005). Foi adotado um nível de significância $\alpha$ de 0,05 . Para a execução desse procedimento foi utilizado o software R ( $\mathrm{R}$ DEVELOPMENT CORE TEAM, 2008).

No primeiro momento, a densidade básica foi avaliada considerando-se todas as espécies e, em seguida, considerando-se as espécies que ocorreram em mais de duas fitofisionomias. Gráficos de barras, de distribuição de frequências, de dispersão e de tendência, foram confeccionados para melhor visualização e análise dos resultados.

\section{RESULTADOS E DISCUSSÃO}

$\mathrm{Na}$ Tabela 1, encontra-se a análise de variância para a densidade básica da madeira no delineamento considerado. Observa-se que o efeito da fitofisionomia foi altamente significativo, indicando existir pelo menos uma diferença entre elas.

Tabela 1 - Análise de variância da densidade básica da madeira nas fitofisionomias.

Table 1-Analysis of variance of wood density in vegetation types.

\begin{tabular}{lccccc}
\hline FV & GL & SQ & QM & Fc & Valor-p \\
\hline Fitofisionomia & 4 & 3,0686 & 0,7672 & 64,062 & $0,000^{*}$ \\
Erro & 1983 & 23,7467 & 0,0120 & & \\
Total corrigido & 1987 & 26,8154 & & & \\
\hline CV(\%) & 18,5 & & & & \\
Média geral & 0,588 & $\mathrm{n}=$ & 1988 & & \\
\hline
\end{tabular}

em que: $*$ = significativo.

$\mathrm{Na}$ Tabela 2, estão apresentadas as descrições da densidade básica da madeira por fitofisionomia para 0 estado de Minas Gerais, justamente com a comparação múltipla realizada. Tem-se que todas as amostras utilizadas apresentaram-se suficientes a 95\% de confiança com erro máximo de $5 \%$. Esse resultado indica que as estimativas das densidades da madeira foram precisas, o que resulta em baixos erros e intervalos de confiança estreitos que garantem estimativas próximas ao parâmetro verdadeiro da densidade da madeira.

Tabela 2 - Descrição da densidade básica da madeira por fitofisionomia no Estado de Minas Gerais.

Table 2 - Description of basic wood density within vegetation types in Minas Gerais state.

\begin{tabular}{lccccc}
\hline \multirow{2}{*}{ Fitofisionomia } & $\mathrm{n}$ & $\mathrm{DB}$ & $\mathrm{EP}$ & $\mathrm{LI}$ & $\mathrm{LS}$ \\
\cline { 3 - 6 } & & \multicolumn{4}{c}{$\left(\mathrm{g} . \mathrm{cm}^{-3}\right)$} \\
\hline Ombrófila & $152^{*}$ & $0,502 \mathrm{a}$ & 0,0084 & 0,486 & 0,519 \\
Semidecídua & $669^{*}$ & $0,561 \mathrm{~b}$ & 0,0045 & 0,552 & 0,569 \\
Cerradão & $174^{*}$ & $0,585 \mathrm{c}$ & 0,0079 & 0,569 & 0,600 \\
Cerrado típico & $869^{*}$ & $0,612 \mathrm{~d}$ & 0,0035 & 0,606 & 0,619 \\
Decídua & $124^{*}$ & $0,675 \mathrm{e}$ & 0,0118 & 0,651 & 0,698 \\
\hline
\end{tabular}

em que: $\mathrm{n}=$ tamanho da amostra; $*=$ amostra suficiente a $95 \%$ de confiança com erro admissível de $5 \%$; DB $=$ densidade básica média; $\mathrm{EP}=$ erro padrão; $\mathrm{LI}=$ limite inferior; $\mathrm{LS}=$ limite superior; Médias de densidade básica seguidas de mesma letra não se diferem a $5 \%$ de significância.

Cerne, Lavras, v. 18, n. 2, p. 345-352, abr./jun. 2012 
Notoriamente, pela Tabela 2, observa-se que houve diferença estatística significativa entre todas as fisionomias florestais. As fitofisionomias ombrófila, semidecídua, cerradão, cerrado típico e decídua apresentaram médias de densidade de 0,$502 ; 0,561 ; 0,585 ; 0,612$ e 0,675 g.cm ${ }^{-3}$, respectivamente. Observa-se que a formação ombrófila apresentou valores médios de densidade inferior às demais, contrastando o resultado da floresta decidual. As fitofisionomias semidecídua, cerrado típico e cerradão apresentaram valores médios mais próximos, mas ainda assim diferentes estatisticamente.

Para facilitar a análise, as densidades médias da madeira com os respectivos intervalos de confiança e a dispersão das observações por fitofisionomias foram apresentadas graficamente de forma crescente na Figura 2.

Foi possível notar que a amplitude das observações de densidade da madeira é elevada e relativamente semelhante entre as fitofisionomias, mostrando que independente da formação florestal, pode-se encontrar indivíduos tanto com baixa como com alta densidade da madeira. No entanto, a concentração de indivíduos é diferenciada, principalmente considerando as florestas ombrófila e decídua, em que a concentração de indivíduos de baixa e de alta densidade, respectivamente, foi claramente observada. Nas fitofisionomias semidecídua, cerradão e cerrado típico não foi possível visualizar, em razão da sobreposição das observações, mas as barras de médias e a linha de tendência indicam um padrão crescente de concentração entre essas fitofisionomias.

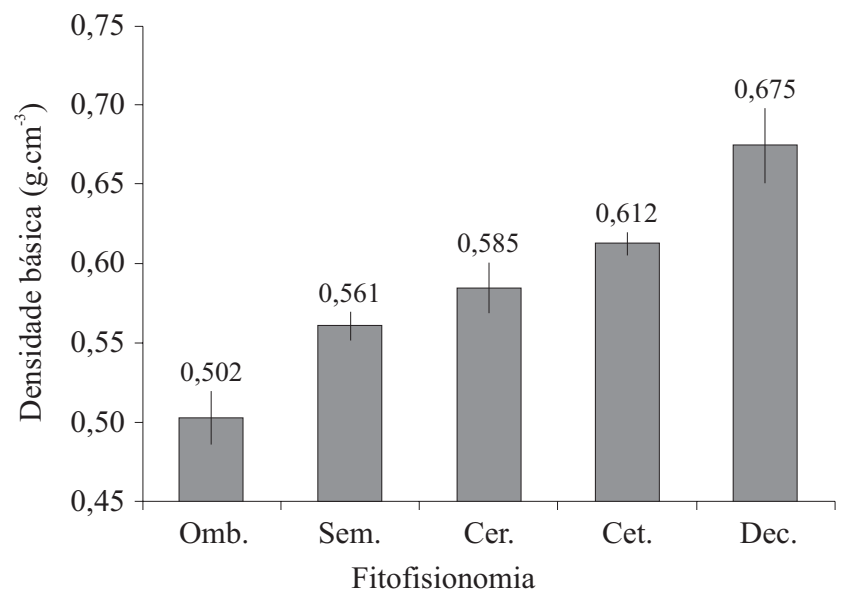

Segundo a classificação da vegetação brasileira (VELOSO et al., 1991), a floresta ombrófila é caracterizada por elevadas temperaturas médias, elevadas precipitações com boa distribuição ao longo do ano, apresentando de zero a apenas 60 dias sem chuva, o que determina uma situação biológica praticamente sem períodos secos. Já a formação decidual é caracterizada por duas estações climáticas bem demarcadas, uma chuvosa seguida de longo período biologicamente seco com mais de 50\% dos indivíduos sem folhas no período desfavorável. Portanto, ambientes absolutamente díspares em termos de condições ambientais, sendo que a fitofisionomia ombrófila apresenta características favoráveis à atividade fisiológica das plantas, corroborando para as densidades da madeira substancialmente mais baixas. Assim como a floresta decidual, com condições opostas, foi coerente com as densidades mais altas. Roque e Tomazello Filho (2009) afirmaram que árvores crescendo em clima tropical seco produzem madeira de maior densidade do que aquelas de clima tropical úmido.

Em relação à formação semidecidual, a mesma é caracterizada por dupla estacionalidade climática. Uma tropical com época de intensas chuvas de verão seguida por estiagens acentuadas e outra subtropical sem período seco, mas com temperaturas médias baixas. Em tal tipo de vegetação, a porcentagem das árvores caducifólias no conjunto florestal situa-se entre 20 e $50 \%$ (VELOSO et al., 1991). Com essas características ambientais, essa fitofisionomia apresentou densidade

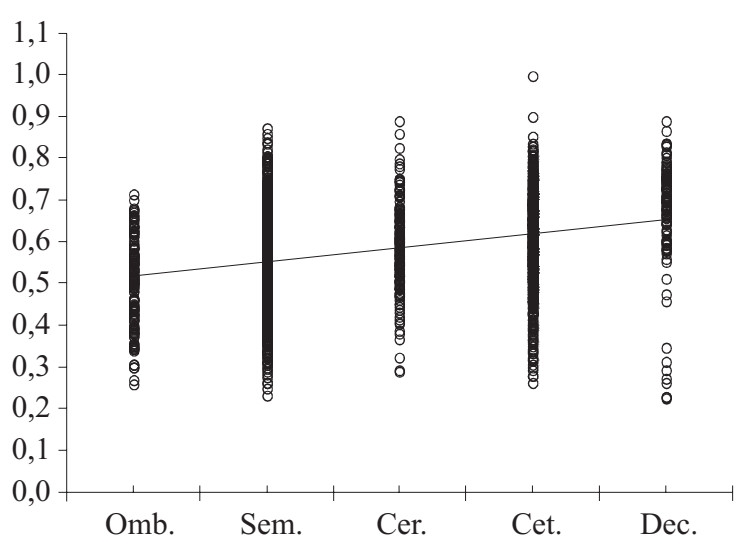

Figura 2 - Médias e dispersão da densidade básica da madeira entre as fitofisionomias no estado de Minas Gerais. Em que: Cer. $=$ Cerradão; Cet. $=$ Cerrado típico; Dec. $=$ Decídua; Omb. $=$ Ombrófila; Sem. $=$ Semidecídua.

Figure 2 - Mean and dispersion of wood density in vegetation types in Minas Gerais state. Cer. = Savanna woodland; Cet. = Typical savanna; Dec. = Deciduous forest; Omb. = Ombrophylous forest; Sem. = Semideciduous forest .

Cerne, Lavras, v. 18, n. 2, p. 345-352, abr./jun. 2012 
média da madeira mais alta que a floresta ombrófila e mais baixa quando comparada aos cerrados e à floresta decidual. Fato que pode ser justificado, uma vez que a ocorrência de florestas estacionais semideciduais coincide com solos mais férteis, úmidos e profundos (OLIVEIRA-FILHO et al., 1994), assim como, associada a teores mais elevados de matéria orgânica, nutrientes em superfície, argilominerais, argila em todo o perfil e maior potencial de uso da água disponível pelas plantas, quando comparadas aos cerrados (ROSSI et al., 2005). Logo, essa fitofisionomia é capaz de melhor suprir as plantas com água nos períodos mais secos, bem como propiciar maior fertilidade ativa advinda da ciclagem de nutrientes da matéria orgânica e, consequentemente, propiciando atividade fisiológica mais acentuada quando comparada aos cerrados e à floresta decidual e, portanto, concordando com densidades da madeira mais baixas.

As fisionomias cerradão e cerrado típico, mesmo pertencentes ao mesmo bioma (Cerrado), apresentaram diferença significativa quanto à densidade média da madeira. A ocorrência das cinco diferentes fisionomias do bioma Cerrado está relacionada a fatores edáficos, topográficos, clima sazonal, condições hídricas, fenologia e forma de dispersão das espécies, incidência de fogo e perturbações antrópicas (AGNES et al., 2007; OLIVEIRAFILHO et al., 1990; OLIVEIRA-FILHO; FLUMINHANFILHO, 1999). O fato das densidades serem próximas, provavelmente, deve-se a semelhança na composição florística e edafoclimáticas apresentadas particularmente entre essas duas fisionomias do Cerrado. Estudos comparativos entre essas duas formações mostram índices de similaridade florística médios a altos, em torno de 35 a 73\% (COSTA; ARAÚJO, 2001; RIBEIRO et al., 1985), com ocorrência em solos distróficos profundos, bem drenados, de baixa fertilidade, com acidez e teor de alumínio muito semelhantes (AGNES et al., 2007; COSTA; ARAÚJO, 2001; MARIMON JUNIOR; HARIDASAN, 2005) e em clima tropical estacional com verões quentes e úmidos e inverno ameno e seco com duração aproximada de seis meses (AGNES et al., 2007; VELOSO et al., 1991). Segundo Marimon Junior e Haridasan (2005), uma das explicações plausíveis em relação à existência das duas fitofisionomias está associada à composição granulométrica dos solos. $\mathrm{O}$ solo sob cerradão, mais argiloso, tem maior capacidade de retenção de água disponível, o que é corroborado por Spera et al. (2005). Portanto, para Marimon Junior e Haridasan (2005), esse solo é capaz de suprir mais adequadamente as plantas com água nos processos de síntese de biomassa, bem como possui maior fertilidade ativa, pois a disponibilidade de água regula a dinâmica dos nutrientes no solo e sua absorção pelas plantas. Essas características, provavelmente, propiciam atividade fisiológica pouco mais acentuada que no cerrado típico e, portanto, pode acarretar a formação de madeira de densidade mais baixa, explicando o padrão encontrado.

$\mathrm{Na}$ Figura 3, visualiza-se o comportamento da concentração de indivíduos em suas respectivas classes de densidades da madeira nas fitofisionomias.

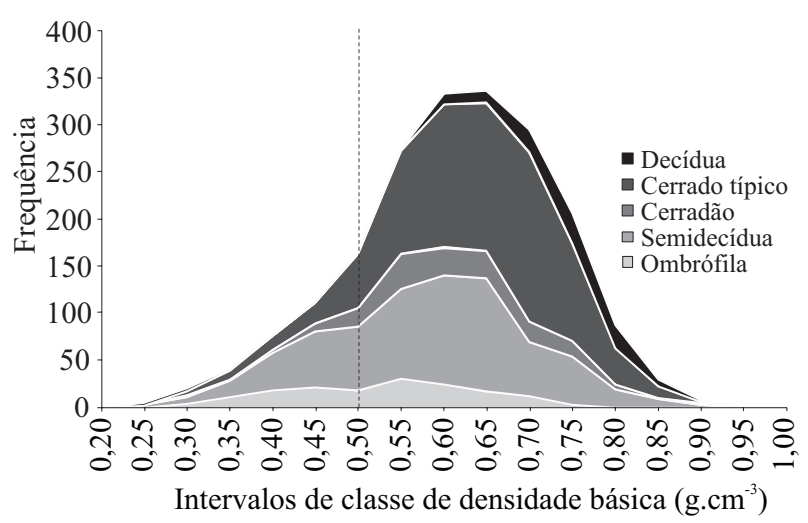

Figura 3 - Distribuição de frequência acumulada de indivíduos nas classes de densidade básica da madeira por fitofisionomia.

Figure 3 - Cumulative frequency distribution of individuals in wood density classes per vegetation type.

Pode-se notar o acúmulo de indivíduos nas maiores classes de densidade da madeira à medida que se percorre da fitofisionomia ombrófila até a decidual. O deslocamento das distribuições dos indivíduos nas fitofisionomias à direita da linha de referência permite observar que há um claro gradiente crescente de indivíduos de maiores densidade à medida que os ambientes se tornam mais adversos à atividade fisiológica das plantas.

De acordo com Rodrigues et al. (2003), a diversidade de fatores ambientais que interagem, afetam a comunidade vegetal e induzem respostas das espécies a esses fatores, fazendo com que cada local tenha características próprias, possibilitando observar tendências. Segundo Nogueira et al. (2007), estudos têm geralmente assumido que a variação na densidade da madeira nos ambientes é puramente advinda da variação na composição de espécies. No entanto, segundo Chave et al. (2006), as variações de determinados fatores ambientais podem conduzir a determinados padrões de composição de espécies e também de densidade da madeira. Portanto,

Cerne, Lavras, v. 18, n. 2, p. 345-352, abr./jun. 2012 
a própria composição florística, determinada pelas condições ambientais, pode ser responsável pela variação da densidade da madeira entre ambientes. Mas, certamente, pode-se afirmar que as densidades das madeiras dos indivíduos que compõe as fitofisionomias apresentaram uma clara e concisa tendência de variarem também em função dos fatores ambientais. Sendo que condições ambientais favoráveis à atividade fisiológica das plantas acarretaram, sensivelmente, uma maior concentração de indivíduos com densidade da madeira mais baixas e o inverso ocorrendo para as condições desfavoráveis.

Com o intuito de reduzir, em parte, o efeito da composição de espécies sobre a variação da densidade da madeira e destacar o efeito do ambiente, na Figura 4 estão apresentadas as médias e tendências levando em

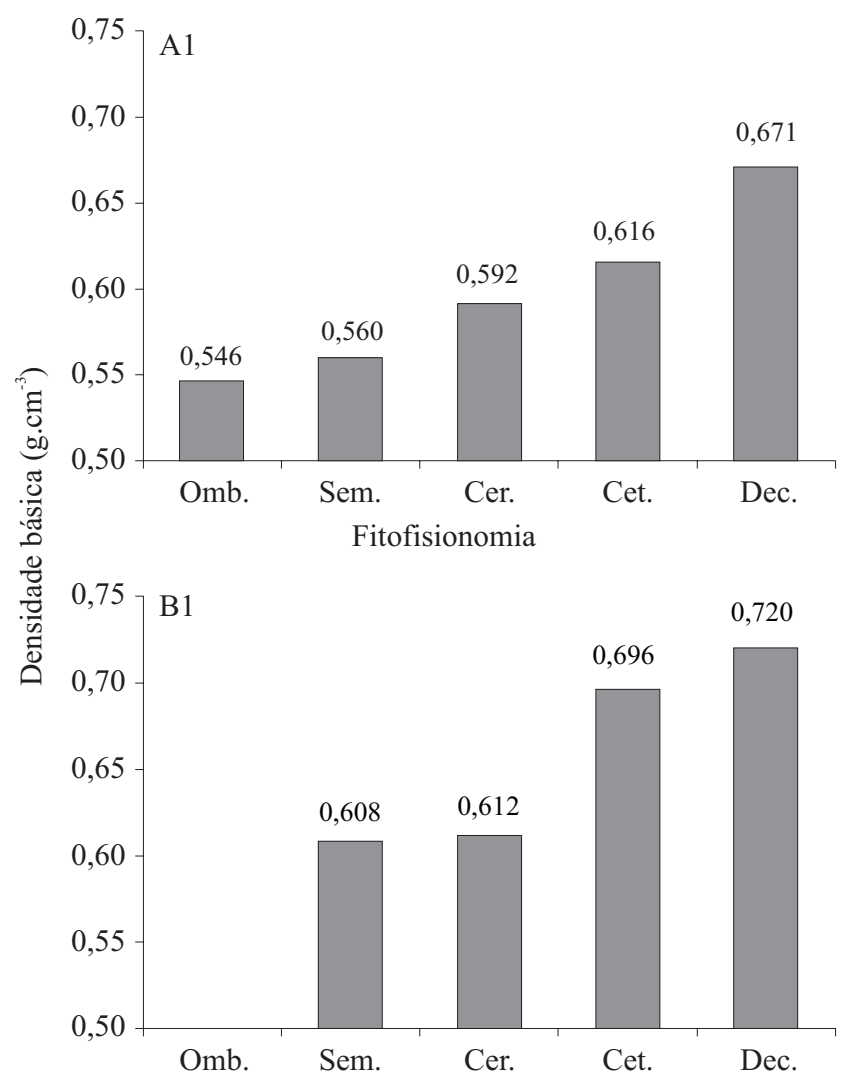

consideração o efeito das espécies que ocorreram em três (Figura 4 A) ou quatro (Figura 4 B) fitofisionomias, independentemente e simultaneamente. Foram excluídas as espécies que ocorrem exclusivamente em uma ou duas formações e não foram amostradas espécies que ocorrem nas cinco fitofisionomias simultaneamente.

Com base na Figura 4 A, observa-se que, mesmo retirando as espécies amostradas exclusivamente em uma e duas fitofisionomias, o padrão de variação da densidade da madeira encontrado anteriormente se manteve. Sendo a hierarquia entre as fitofisionomias exatamente a mesma e os valores absolutos de densidade muito semelhantes, exceto para ombrófila. Desse modo, pode-se reafirmar o efeito ambiental, uma vez que ele se manteve mesmo com certa redução do fator específico.
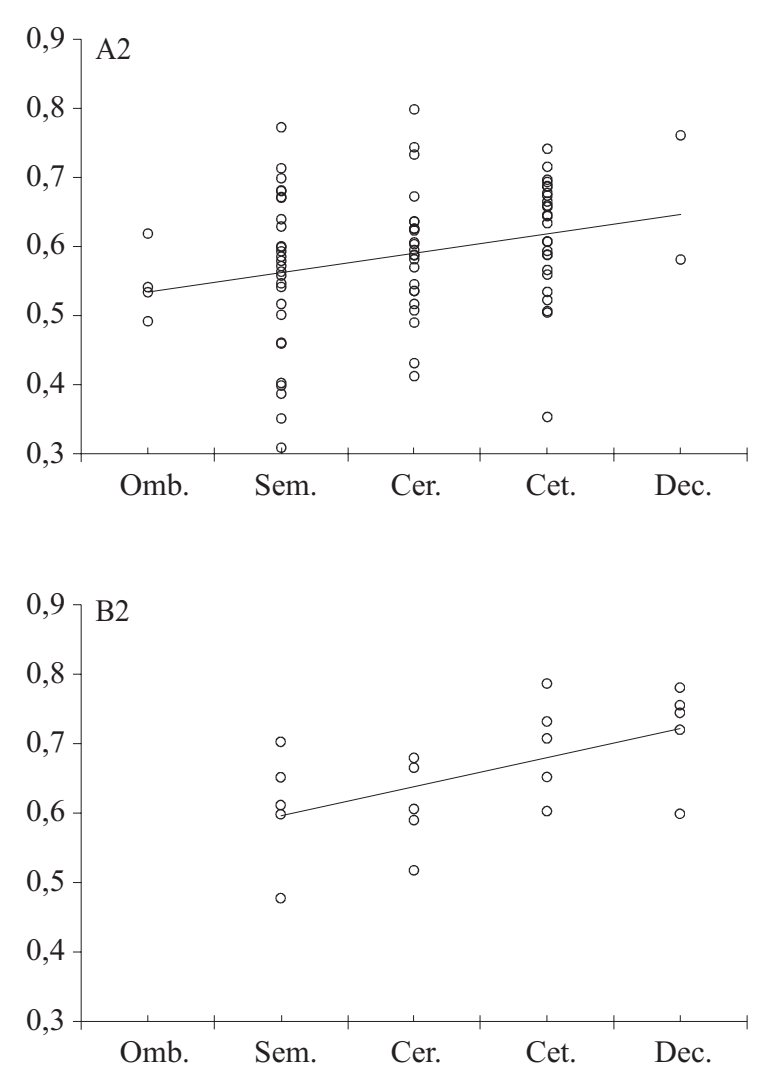

Figura 4 - Médias e tendência da densidade básica da madeira nas fitofisionomias para as espécies em comum. Sendo em A, as espécies que ocorrem em três fitofisionomias independente e simultaneamente e em B as espécies que ocorrem em quatro. Em que: Cer. $=$ Cerradão; Cet. $=$ Cerrado típico; Dec. $=$ Decídua; Omb. $=$ Ombrófila; Sem. $=$ Semidecídua .

Figure 4-Means and trends of wood basic density in vegetation types for species in common. Where A, species that occur in three vegetation type simultaneously and independently, and B, species that occur in four vegetation type. Cer. = Savanna woodland; Cet. $=$ Typical savanna; Dec. $=$ Deciduous forest; Omb. $=$ Ombrophylous forest; Sem. $=$ Semideciduous forest .

Cerne, Lavras, v. 18, n. 2, p. 345-352, abr./jun. 2012 
Em relação à Figura 4B, como não houve observações na floresta ombrófila e como estão representadas apenas as espécies que ocorrem simultaneamente em quatro fitofisionomias, estas foram exatamente as mesmas em cada uma delas: Anadenanthera colubrina, Myracrodruon urundeuva, Myrcia splendens, Plathymenia reticulata e Terminalia fagifolia. Dessa forma, todo efeito em termos de composição de espécies sobre a variação da densidade média da madeira entre as fitofisionomia é nulo, e mesmo com poucas observações, o padrão ainda assim se manteve. Sendo que a média de densidade da madeira nas formações semidecídua e cerradão foram consideravelmente inferiores ao cerrado típico e floresta decidual. Apesar da hierarquia ter sido a mesma, deve-se ressaltar que as diferenças entre as densidades médias foram reduzidas entre a semidecídua e o cerradão, assim como entre o cerrado típico e a decídua. Fato que indica que a composição de espécies também tem efeito relevante na variação na densidade da madeira nas fitofisionomias, assim como o efeito ambiental verificado.

\section{CONCLUSÕES}

Há uma relação clara e coerente da densidade da madeira com as características ambientais que condicionam as diferentes fitofisionomias no estado de Minas Gerais. As fitofisionomias ombrófila, semidecídua, cerradão, cerrado típico e decídua, apresentam, nessa ordem, um gradiente crescente de características ambientais desfavoráveis à atividade fisiológica e cambial das plantas, resultando em um padrão crescente de concentração de indivíduos e espécies com densidades da madeira mais elevada. Portanto, a variação da densidade da madeira nos ambientes é tanto determinada pela variação da composição florística como pelos fatores ambientais.

\section{REFERÊNCIAS}

AGNES, C. C.; CALEGARI, L.; GATTO, D. A.; STANGERLIN, D. M. Fatores ecológicos condicionantes da vegetação do cerradão. Caderno de Pesquisa Série Biologia, Rio de Janeiro, v. 19, n. 3, p. 25-37, 2007.

ANTONOVA, G. F.; STASOVA, V. V. Effects of environmental factors on wood formation in larch (Larix sibirica Ldb.) stems. Trees - Structure and Functional, San Diego, v. 11, n. 8, p. 462-468, 1997.

ASSOCIAÇÃO BRASILEIRA DE NORMAS TÉCNICAS. NBR 7190: determinação da massa específica básica da madeira. Rio de Janeiro, 1997.
BAKER, T. R.; PHILLIPS, O. L.; MALHI, Y.; ALMEIDA, S.; ARROYO, L.; DI FIORE, A.; KILLEEN, T. J.; LAURANCE, S. G.; LAURANCE, W. F.; LEWIS, S. L.; LLOYD, J.; MONTEAGUDO, A.; NEILL, D. A.; PATIÑO, S.; PITMAN, N. C. A.; SILVA, N.; MARTÍNEZ, R. V. Variation in wood density determines spatial patterns in Amazonian forest biomass. Global Change Biology, Oxford, v. 10, n. 5, p. 545$562,2004$.

BERGÈS, L.; NEPVEU, G.; FRANC, A. Effects of ecological factors on radial growth and wood density components of sessile oak (Quercus petraea Liebl.) in Northern France. Forest Ecology and Management, Amsterdam, v. 255, n. 3/4, p. $567-579,2008$.

CHAVE, J.; MULLER-LANDAU, H. C.; BAKER, T. R.; EASDALE, T. A.; STEEGE, H.; WEBB, C. O. Regional and phylogenetic variation of wood density across 2,456 neotropical tree species. Ecology Applicate, Oxford, v. 16, n. 6, p. 56-67, 2006

COSTA, A. A.; ARAÚJO, G. M. Comparação da vegetação arbórea de cerradão e de cerrado na Reserva do Panga, Uberlândia, Minas Gerais. Acta Botanica Brasilica, Porto Alegre, v. 15, n. 1, p. 63-72, 2001.

FERREIRA, D. F. Estatística básica. Lavras: UFLA, 2005. $650 \mathrm{p}$.

FERREIRA, D. F. SISVAR: um programa para análises e ensino de estatística. Revista Symposium, Lavras, v. 6, p. 36-41, 2008.

MARIMON JUNIOR, B. H.; HARIDASAN, M. Comparação da vegetação arbórea e características edáficas de um cerradão e um cerrado sensu stricto em áreas adjacentes sobre solo distrófico no leste de Mato Grosso, Brasil. Acta Botanica Brasilica, Porto Alegre, v. 19, n. 4, p. 913-926, 2005.

MULLER-LANDAU, H. C. Interspecific and intersite variation in wood density of tropical trees. Biotropica, Washington, v. 36, n. 1, p. 20-32, 2004.

NOGUEIRA, E. M.; FEARNSIDE, P. M.; NELSON, B. W.; FRANÇA, M. B. Wood density in forests of Brazil's 'arc of deforestation': implications for biomass and flux of carbon from land-use change in Amazonia. Forest Ecology and Management, Amsterdam, v. 248, n. 3, p. 119-135, 2007.

Cerne, Lavras, v. 18, n. 2, p. 345-352, abr./jun. 2012 
OLIVEIRA FILHO, A. T.; FLUMINHAN FILHO, M. Ecologia da vegetação do Parque Florestal Quedas do Rio Bonito. Cerne, Lavras, v. 5, n. 2, p. 51-64, jul./dez. 1999.

OLIVEIRA-FILHO, A. T.; SHEPHERD, G. J.; MARTINS, F. R.; STUBBLEBINE, W. H. Environmental factors affecting physiognomic and floristic variation in an area of cerrado in central Brazil. Journal of Tropical Ecology, Cambridge, v. 5, p. 413-451, 1990.

OLIVEIRA-FILHO, A. T.; VILLELA, E. A.; CARVALHO, D. A.; GAVILANES, M. L. Differentiation of streamside and upland vegetation in an area of montane semideciduous forest in southeaster, Brazil. Flora, London, v. 189, p. 287-305, 1994.

R DEVELOPMENT CORE TEAM. R: a language and environment for statistical computing. Vienna: R Foundation for Statistical Computing, 2008. Disponível em: $<$ http:// www.R-project.org>. Acesso em: 10 mar. 2010.

RIBEIRO, J. F.; SILVA, J. C. S.; BATMANIAN, G. J. Fitossociologia de tipos fisionômicos de cerrado em Planaltina, DF. Revista Brasileira de Botânica, São Paulo, v. 8, p. 131-142, 1985.

RIGATTO, P. A.; DEDECEK, R. A.; MATOS, J. L. M. Influência dos atributos do solo sobre a qualidade da madeira de pinus taeda para produção de celulose kraft. Revista Árvore, Viçosa, v. 28, n. 2, p. 267-273, mar./abr. 2004.

RODRIGUES, L. A.; CARVALHO, D. A.; OLIVEIRA FILHO, A. T.; BOTREL, R. T.; SILVA, E. A. Florística e estrutura da comunidade arbórea de um fragmento florestal em Luminárias, MG. Acta Botanica Brasilica, Porto Alegre, v. 17, p. 71-97, 2003.

ROQUE, R. M.; TOMAZELLO FILHO, M. Variação radial da estrutura anatômica do lenho de árvores de Gmelina arborea em diferentes condições de clima e de manejo na Costa Rica.
Scientia Forestalis, Piracicaba, v. 37, n. 83, p. 273-285, set. 2009.

ROSSI, M.; MATTOS, I. F. A.; COELHO, R. M.; MENK, J. R. F.; ROCHA, F. T.; PFEIFER, R. M.; MARIA, I. C. Relação solos-vegetação em área natural no Parque Estadual de Porto Ferreira, São Paulo. Revista do Instituto Florestal, São Paulo, v. 17, n. 1, p. 45-61, 2005.

RUFINI, A. L.; SCOLFORO, J. R. S.; OLIVEIRA, A. D.; MELLO, J. M. Equações volumétricas para o Cerrado Sensu Stricto, em Minas Gerais. Cerne, Lavras, v. 16, n. 1, p. 1-11, jan./mar. 2010.

SCOLFORO, J. R. S.; OLVEIRA, A. D.; ACERBI, J. F. W. Inventário florestal de Minas Gerais: equações de volume, peso de matéria seca e carbono para diferentes fisionomias da flora nativa. Lavras: UFLA, 2008. 216 p.

SHIVER, B. D.; BORDERS, B. E. Sampling techniques for forest resource inventory. New York: J. Wiley, 1996. 356 p.

SPERA, S. T.; REATTO, A.; MARTINS, E. de S.; CORREIA, J. R. Atributos físicos de solos e distribuição das fitofisionomias de cerrado na bacia hidrográfica do Rio Jardim, DF. Boletim de Pesquisa e Desenvolvimento, Planaltina, v. 146, p. 1-18, 2005.

TROVATI, L. R.; FERRAZ, E. S. B. Influência da precipitação e da temperatura na densidade dos anéis de crescimento de Pinus oocarpa. IPEF, Piracicaba, n. 26, p. 31-36, abr. 1984.

VELOSO, H. P.; RANGEL FILHO, A. L. R.; LIMA, J. C. A. Classificação da vegetação brasileira adaptada a um sistema universal. Rio de Janeiro: IBGE, 1991. 124 p.

VILLAR, P.; CASTRO, P.; PÉREZ, P.; MONTSERRATMARTÍ, G. Stem xylem features in three Quercus (Fagaceae) species along a climatic gradient in NE Spain. Trees Structure and Function, San Diego, v. 12, n. 2, p. 90-96, 1997.

Cerne, Lavras, v. 18, n. 2, p. 345-352, abr./jun. 2012 